INTERNATIONAL PUBLIC PROCUREMENT CONFERENCE PROCEEDINGS, VOLUME 32004

\title{
PURCHASING CONTROL, COMPLIANCE AND THE BOX: PURCHASING MANAGEMENT BASED ON HARD DATA
}

\author{
Jan Telgen*
}

\begin{abstract}
Purchasing management is often approached as a qualitative art. Experience, insight and managerial qualities may indeed make useful contributions. However, in addition to this, the possibilities of an approach based on hard data and figures should not be underestimated. This does not only apply to purchases dealt with by the Purchasing Department, but in particular, also to purchasing activities outside of the Purchasing Department. Correct application of quantitative approaches provides additional insight and contributes to a valuable role of the purchasing function in the entire business process.
\end{abstract}

\section{INTRODUCTION}

It is well known that a large part of the activities in the purchasing process are initiated by other people than procurement officers. Technical requirements are often set by the experts concerned and process owners, orders are placed by users and payments are settled by the Finance Department.

This may be the case as a result of a conscious choice in accordance with the orgnisation's policy. For example, employing temporary staff is taken care of by a Human Resources Department or taking out insurances policies by a Finance Department. However, this also happens more or less "by accident". These may be genuine mistakes, but there are certainly also a large number of "deliberate mistakes". In practice, other terms are being used, as a result of which these activities are not considered to be purchasing activities. Renewal of a contract, investment, expenditure or (popular with public organisations in the field of public works): invitations to tender are suddenly no longer considered to be purchases.

* Jan Telgen, Ph.D., is Professor of Applied Operations Research and the NEVI Professor of Purchasing Management at the University of Twente, Enschede, the Netherlands. In addition, he is a partner with the consulting firm Significant and president of the Netherlands Platform for Public Procurement. 
It also happens that procurement officers and Purchasing Departments are deliberately ignored. Departmental managers held responsible for the department's results, realise only too well that purchasing is one way to influence the result they are judged by. Many of them prefer their own direct influence on purchasing activities and ignore the head office or central purchasing departments in such a situation.

Fighting such situations by an "obligation to call on the Purchasing Department" does not work. The clearest example of this was the obligation (even included in Dutch law) for Dutch public servants to call in the then State Procurement Office, until 1992. At the end of the eighties, only about 3\% met this legal obligation.

It has to be accepted as an established fact that purchasing activities (including the conclusion of contracts) also take place outside the Purchasing Department. However, this does not mean that these activities cannot be managed.

\section{COMING TO GRIPS WITH PURCHASING}

A very useful and frequently used definition of 'Purchasing' is: "Purchasing is anything resulting in an invoice" (Telgen, 1994). This definition can directly be made operational in a number of practical aids for management and control of the purchasing function. For example, this definition implies that the total purchasing expenses can be obtained from the financial administration.

In principle, two approaches can be used to come to grips with purchasing activities, which may also be used in combination with each other.

In the first and future-oriented approach, the spend per category of goods and services (commodity categories) may, in broad lines, be derived beforehand from estimates and budgets. With this information, plans could be drawn up for RFQ's. However, usually this information is not detailed enough to be able to determine what exactly needs to be purchased and when.

Therefore, a second and history-oriented approach is frequently used: a spend analysis. A spend analysis is in fact nothing more than analysing all purchases afterwards. This can be done relatively easily by means of the definition of purchasing as stated above: "Purchasing is anything resulting in an invoice". Invoices are usually paid (and if they are not 
paid, the supplier will sound the alarm) and all payments eventually end up in an administration called Accounts Payable (in the US: Expenditures). Thus Accounts Payable is the starting point for a spend analysis. This analysis sometimes goes under other names like purchasing diagnosis or purchasing scan.

\section{SPEND ANALYSIS IN LITERATURE}

Spend analysis does not appear to be a very common subject in the academic purchasing literature. Although some papers briefly mention spend analysis as a tool (see, for example, Carter (2003) and Smeltzer and Ruzicka (2000)), they provide no description of exactly how spend analysis should be carried out.

However, the importance of consolidation of purchase volumes is discussed widely in literature. Spend analysis provides insight in opportunities for these consolidations. Monckza et al. (2002) identify this as a trend in purchasing activity: 'there will be an increased purchase volume accumulation or consolidation', given the current emphasis on cost reduction.

Nelson et al. (2001) strongly emphasize the importance of good analysis of the consolidated purchasing data in an organization, in order to find opportunities for the consolidation of purchases volumes. But they do not give a method to perform this analysis.

In contrast to the academic literature, more popular purchasing literature is increasingly paying attention to spend analysis as a way to cut costs (Millen Porter, 2003; Purchasing, 2004). Due to the developing information technology, it becomes easier and less expensive to analyze spend, compared to time consuming manual methods. The number of spend analysis vendors is rapidly growing, their spend analysis tools are either provided in separate software packages, or integrated in ERP or eprocurement software. However, at the same time, with the plethora of information systems it is sometimes harder to analyze spend. Spend data are spread across different systems like order management systems, accounts payable, accounts receivable, inventory management systems and ERP systems. Organisations find it hard to collect and compare all data available (Howarth and Wynen, 2003).

It is important to note the difference between spend analysis and cost analysis related to purchasing. In contrast to spend analysis, different 
purchasing cost analysis techniques (such as target cost analysis, total cost of ownership and open book analysis) have received much attention in literature. Ellram (1995) gives an overview of these techniques and a way for organizations to determine the right type of cost analysis for a certain purchase (based on the impact of the purchase and the type of relationship sought with the supplier). Cost analysis tries to ensure a fair price for a single purchase, based on the assumed or calculated cost of this item (Ellram, 1995). However, spend analysis does not focus on the cost of a single item, but aims to reduce the cost of the organization's purchases as a whole. It analyses how the purchasing of a given set of purchases can be performed in a more efficient and cost effective way.

\section{SPEND ANALYSIS IN PRACTICE}

The Accounts Payable records do not have to be analysed as part of the accounting system, which the organisation uses for its administration. It can just as well be done by analysing a copy (a download) of the records, which does not burden the daily administrative activities.

When making the analysis, only four types of data per invoice are essential in accounts payable: the amount paid, the supplier, the cost category (commodity) and cost centre (organizational classification like department / agency). There is often more data available in accounts payable, but this data is not required for making the spend analysis. However, before starting it should be considered the data is often not perfect.

The amounts and suppliers are usually correct, but they do require processing, for example, when there are different currencies (sometimes) and different names, different business locations or spelling of supplier's names (the number of unique supplier's names can often be reduced by $25-50 \%$ by removing duplicate names).

Cost categories are converted (usually, grouped) into commodity categories and cost centres into departments. The cost centres (departments) are usually correct, even though at times, projects are involved that are hard to classify as cost centres.

However, a serious warning is in order with reference to the cost categories. Often, hundreds or thousands of code numbers are used and mistakes in coding are easily made. Although these mistakes do lead to a 
TABLE 1

Basis for the Spend Analysis

\begin{tabular}{|c|l|l|l|l|l|r|}
\hline Amount & $\begin{array}{l}\text { Account } \\
\text { no. }\end{array}$ & Name & Cost centre & Cost category & No. & Other \\
\hline$€ 541$ & 12345 & Janssen & Department A & $\begin{array}{l}\text { Garden } \\
\text { maintenance }\end{array}$ & $\begin{array}{l}\text { Date, } \\
\text { agent, etc. }\end{array}$ \\
\hline$€ 1411$ & 54321 & De Fret & BU 6 & Catering & 2 & $\ldots \ldots .$. \\
\hline$\ldots$ & & & & & & \\
\hline$\ldots$ & & & & & & \\
\hline$\ldots$ & & & & & & \\
\hline$\ldots$ & & & & & & \\
\hline & $=$ Supplier & = Department & $\begin{array}{l}\text { Commodity } \\
\text { category }\end{array}$ & $\begin{array}{l}\text { Not for further } \\
\text { use }\end{array}$ \\
\hline
\end{tabular}

Source: Lenselink and Telgen (1998)

distortion of the picture on a detailed level, they do not influence the total performance of the organisation whatsoever. Thus, mistakes remain unnoticed, until a spend analysis is made. Mistakes in the cost categories (use of the wrong code) are made by accident, but also on purpose, for example, because the budget has run out in one cost category, while it has not run out in another cost category. So people "use the wrong code". This calls for verification and, if necessary, recoding of the data in this category in order to make a proper spend analysis.

Besides, there often are so many invoices that manual processing and manual analysis are not advisable. Nowadays, for that purpose specific software is frequently used (Telgen, 2003).

The analysis itself is made up of selecting and sorting the data of each invoice in order to gain insight into matters such as the purchasing volume for each package, each supplier and in each department. The following examples are more or less standard items:

- Purchasing turnover in each department;

- Purchasing turnover for each commodity category;

- Number of suppliers for each commodity category; 
- Number of invoices for each commodity category;

- Number of invoices for each supplier;

- Number of departments to which a supplier delivers, for each supplier;

- Division of the invoice amount for each supplier;

- Division of the invoice amount for each commodity category;

In a deeper analysis, three-dimensional cross-sections are examined, such as:

- Number of suppliers for each commodity category in each department;

- Number of invoices for each commodity category in each department.

The intended purpose of all cases is making a contribution to the control of the purchasing function, based on data from the spend analysis, by recognising special situations. Commodity categories distributed over large numbers of suppliers, departments buying the same commodity category from different suppliers each time, or suppliers with large numbers of invoices, may give cause for further examination.

In this respect, an observation is in order. Further examination is required before a judgement can be passed. The spend analysis shows nothing of the contents of the contracts or the purchases: a spend analysis shows the volume of the purchases. It is not useful to judge or act on the basis of a spend analysis alone.

\section{PURCHASING CONTROL}

Basically, spend analysis is a once-only activity. A real grip on the purchasing function can only be achieved when activities of the standard planning and control cycle are periodically carried out. These activities are called purchasing control. A periodical spend analysis is part of this procedure (Telgen 1997). In addition to making a spend analysis, purchasing control also means the organisational implementation thereof and the method of handling analyses and their follow-up. Particularly by this broad interpretation of the concept of purchasing control, a contribution can be made to the professionalisation of the purchasing 
function. A professional purchasing function can not exist without purchasing control.

In addition to information supplied to the Purchasing Department (such as: which contracts are/are not used, with which suppliers should invoicing be discussed, and which commodity categories can be consolidated), purchasing control also provides information to the management of the company and the management of the departments (such as: who are the most important suppliers, for what commodity categories do my employees use other suppliers than the rest of the company). In this respect, supplying this information to all those involved is a corner stone for the purchasing function.

An important advantage of purchasing control over a once-only spend analysis is the possibility to introduce monitoring of contract compliance. Contract compliance refers to using framework contracts for the entire company, which can be systematically followed and analysed. In a specific year non-compliance of company contracts could be incidental. If this occurs year after year, the chances of it being incidental are considerably lower, while the necessity for analysis and possibly correction are bigger.

This leads to an important point of attention: by pursuing contract compliance, the purchasing control function will likely come across as an inspection body, as a kind of watchdog. This cannot usually be combined with the position of the interested party or with the party offering assistance. Therefore, it is not practical to position the purchasing control function within the Purchasing Department itself. The company-wide contracts are the ones that are not observed in case of non-compliance, so the purchasing control activities should be positioned with other activities that monitor company-wide actions. The purchasing control function could complement a financial control function, or that of an internal accountant, if any. Even in such an organisational set-up, a broad distribution (of course including the Purchasing Department) of the information found and analyses made is advisable.

Only if there is a CPO in the organisation, who does not deal with tactical purchasing activities himself, but focuses on facilitation, policy making and infrastructure, a combination of the purchasing function and this (CPO) purchasing role is possible. 


\section{THE BOX}

An analysis and representation instrument called the "Telgen Box" (Figure 1) has been developed over the years, to present the information about contract compliance in an unequivocal way (Mulder \& Telgen, 2003). The box makes use of the same information that has been retrieved in a spend analysis. This information is represented in a special way.

The box has two axes: one for the commodity categories and one for contract compliance. On the commodity categories axis, the overall purchasing volume of the organisation (or the department, which will be discussed later) is divided into parts according to the spend on that

\section{FIGURE 1}

The Box

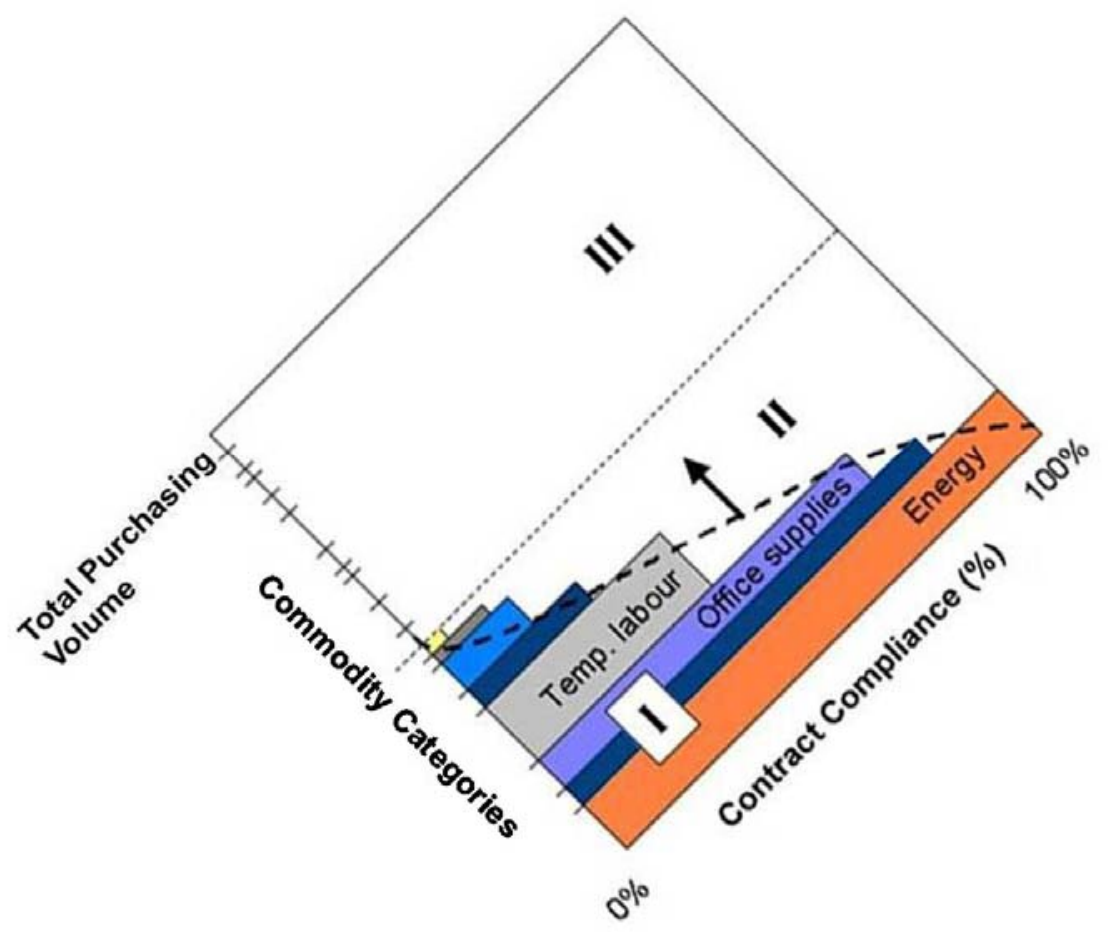


commodity category. The order of the commodity categories on the axis is determined by the score on the other axis.

The contract compliance score for each commodity category is represented on the contract compliance axis. This means that the score of a commodity category of which for example $70 \%$ is purchased from the contracted supplier(s) to the group of companies will be $70 \%$. First, the commodity categories are sorted from low to high contract compliance and then a bar diagram will be made for each commodity category up to the score of the contract compliance. This is how the box is constructed.

Now we divide the box in various areas. The purchasing volume under organisation-wide (framework) contracts is represented by area I. Spend on commodity categories for which company-wide framework contracts exist but are not used, is represented by area II. Framework contracts have not (yet) been concluded for the packages in area III. In this company the percentage of the overall purchasing volume that is spent under company-wide contracts is equal to $\mathrm{I} /(\mathrm{I}+\mathrm{II}+\mathrm{III})$, in figure 2 approximately $25 \%$. This is completely different from the percentage of spend on packages for which framework contracts have been concluded: $(\mathrm{I}+\mathrm{II}) /(\mathrm{I}+\mathrm{II}+\mathrm{III})$. In organisations, this percentage is mistakenly applied as the "reach" of the Purchasing Department (in our figure approximately $50 \%)$.

It is clear that an increase of I, which is linked to a decrease of II, is an objective. After all, it may be expected that company-wide contracts are to be preferred concerning a number of items (terms and conditions, suppliers and contract management).

Decreasing III is a responsibility of the Purchasing Department. Reducing III to a minimum is not an objective in itself: it may be very useful for a number of packages not to strive for company-wide framework contracts.

The Purchasing Department can hardly be held responsible for reducing II. This area represents the company-wide framework contracts that are present but not used. That is a responsibility of the management of the organisation or the department concerned.

This brings forward a second application possibility of the box: the box may be developed both on an overall company level and on a departmental and business unit level. For a comparison of the various departments, it is useful to define: 
alpha(i) = I / (I+II) for department (i).

The alpha(i)'s are a good comparison of the departments, because different activities and different purchasing needs for each department do not have any influence. After all, area III does not count in alpha(i) and I for department (i) is corrected in alpha(i) for the joint volume of (I+II). This implies that the level of alpha(i) for each department is the explicit responsibility of the manager of department (i). Ultimately, he is the one who can be held accountable.

A good example of this is found in a privatised former government organisation. This organisation uses the alpha(i) as a multiplication factor for determination of the annual bonus for departmental managers. An alpha(i) of $50 \%$ thus implies that the bonus to be paid would be halved. Consequently, the departmental managers who were formerly hardly interested in the purchasing performance, will now follow the development of alpha(i) carefully. This generally results in two reactions:

1.Pointing out the existence of company-wide framework contracts to their own employees, which leads to an improved purchasing performance;

2.Requesting the Purchasing Department to conclude (better suitable) framework contracts for certain goods or services. This also leads to a better purchasing performance.

The overriding result of the introduction of the box is the involvement of the Purchasing Department proactively in achieving a better purchasing performance. Another example is a government organisation (without individual bonuses) which is considering linking alpha(i) to the interim budget adjustments for each department. The organisation considered using the Table to this end.

TABLE 2 Able for Budget Correction Based on Alpha(I)

\begin{tabular}{|l|l|}
\hline Alpha(i) & Budget Correction \\
\hline $0-20 \%$ & $-/-2 \%$ \\
\hline $20-40 \%$ & $-/-1 \%$ \\
\hline $40-60 \%$ & 0 \\
\hline $60-80 \%$ & $+1 \%$ \\
\hline $80-100 \%$ & $+2 \%$ \\
\hline
\end{tabular}


In this way, all employees of the department are involved in the pursuit of a better purchasing performance.

\section{CONCLUSION}

By means of spend analysis, purchasing control and the box, hard data can be used to give meaning to control of the purchasing function. As Heijboer (2002) convincingly substantiated, such a quantitative analytical approach is a valuable addition to the purchasing toolkit. Bearing in mind these are hard data of realised and registered purchases, they are highly convincing. This power of persuasion can make an excellent contribution to the professionalisation of the purchasing function.

\section{LITERATURE}

Carter, P. et al. (2003, September). Indirect Spend. CAPS Research Critical Issues Report. Tempe, AZ: CAPSResearch.

Ellram, L (1995). "An Approach to Applying Purchasing Cost Management Tools." Proceedings for the First Worldwide Research Symposium on Supply Chain Management

Heijboer, G.J. (2003). Quantitative Analysis of Strategic and Tactical Purchasing Decisions. Twente, The Netherlands: Twente University Press

Howarth, F., Wynen, S. (2003, April). "Spend Analysis: What Purchasing Professionals Need to Know." eMetaprise Research Note.

Lenselink, M. and Telgen, J. (1998). Inkoopmanagement in de Zorgsector. Deventer, The Netherlands: Kluwer Bedrijfsinformatie.

Millen Porter, A. (2003). "Containing Total Spend." Purchasing, 132 (17): $31-38$

Monckza, R.M., Trent, R.J. \& Handfield, R.B. (2002). Purchasing and Supply Chain Management ( $2^{\text {nd }}$ ed.). Mason: South-Western.

Mulder, M and Telgen, J. (2003). "Besturen van de Inkoopfunctie Met Behulp van Cijfers." In Manifest Professionalisering Inkopen en Aanbesteden (pp. 21-26). Twente, The Netherlands: Significant. 
Nelson, D., Moody, P.E. \& Stegner, J. (2001). The Purchasing Machine. New York: The Free Press.

"Super Spend Analysis." (2004). Purchasing, 133 (5): 28-29

Smeltzer, L., and Ruzicka, M. (2000). "Electronic Reverse Auctions: Integrating the Tool with the Strategic-Sourcing Process." PRACTIX CAPS Research, 3 (4): 1-6

Telgen, J. (1994). Inzicht en Overzicht; de Uitdagingen van Besliskunde en Inkoopmanagement. Oratie, The Netherlands: Universiteit Twente

Telgen, J. (1998). "Inkoopcontrol is Essentieel voor Inkoopfunctie." Tijdschrift voor Inkoop \& Logistiek, 14 (10): 19-20

Telgen, J. (2003). "Inkoopdiagnose in Soorten en Maten." Tijdschrift voor Inkoop \& Logistiek, 19 (10): 23-25 